\title{
Memorial de aprendizagem e a formação do professor: vozes constitutivas da relação aprender/ensinar línguas estrangeiras ${ }^{1}$
}

\section{Learning Memorial and Teacher Education: Constitutive Voices of the Relation Between Learning/Teaching Foreign Languages}

Cristiane C. de Paula Brito*

Universidade Federal de Uberlândia (UFU)

Uberlândia - Minas Gerais / Brasil

Maria de Fátima F. Guilherme**

Universidade Federal de Uberlândia (UFU)

Uberlândia - Minas Gerais / Brasil

RESUMO: O objetivo deste trabalho é discutir uma pesquisa que investigou representações construídas em memoriais de aprendizagem, escritos por professores pré-serviço de línguas estrangeiras (LEs), em uma universidade federal do estado de Minas Gerais. O foco foi não apenas compreender como esses professores significam seus processos de aprendizagem de LE, mas também problematizar os possíveis impactos dessas significações em sua futura vida profissional. A pesquisa adotou uma perspectiva inter/transdisciplinar (Linguística Aplicada, Análise do Discurso francesa e Análise Dialógica do Discurso) para examinar como a LE, o processo de ensino-aprendizagem e os sujeitos são representados. Os resultados acenam que a relação dos professores no que diz respeito às suas experiências de aprendizagem na LE é norteada por representaçôes que revelam sua incompletude, bem como sua constante e contínua interpelação de tornar-se sujeito na LE.

*depaulabrito@gmail.com

** mffguilherme@ileel.ufu.br

${ }^{1}$ As questōes aqui discutidas foram publicadas, em língua inglesa, nos anais do 5th IOLC (International Online Language Conference). Frontiers of Language and Teaching - Vol. 3, 2012, p.13-23. 
PALAVRAS-CHAVE: formação de professores de línguas estrangeiras, memorial de aprendizagem, representações discursivas.

ABSTRACT: The aim of this paper is to discuss a study that investigated representations constructed in learning memorials written by pre-service foreign language (FL) teachers in a federal university of the state of Minas Gerais, Brazil. The focus was not only to understand how these teachers signify their FL learning processes, but also to problematise the possible impacts of these significations on their future professional lives. This research adopted an inter/ transdisciplinary approach (Applied Linguistics, French Discourse Analysis and Dialogical Discourse Analysis) to examine how the FL, the teaching-learning process and the subjects are represented. The findings indicate that teachers' relations concerning their learning experiences in FL are guided by representations that reveal their incompleteness as well as their constant and continuing interpellation to become a subject in FL.

KEYWORDS: foreign language teacher education, learning memorial, discursive representations.

\section{Palavras introdutórias}

"Escrever não é contar as próprias lembranças, suas viagens, seus amores e lutos, sonhos e fantasmas" (DELEUZE, 1997/2008, p.12). Ainda, de acordo com esse autor:

Escrever não é certamente impor uma forma (de expressão) a uma matéria vivida. /.../ Escrever é um caso de devir, sempre inacabado, sempre em via de fazer-se, e que extravasa qualquer matéria vivível ou vivida. É um processo, ou seja, uma passagem de Vida que atravessa o vivível e o vivido (Idem, p.11).

$\mathrm{Na}$ esteira do filósofo mencionado, consideramos memoriais de aprendizagem como uma prática de linguagem na formação do professor de língua estrangeira (LE), no caso deste trabalho, uma prática de linguagem escrita, uma vez que os memoriais aqui analisados foram elaborados por escrito. Isso significa que, ao escreverem sobre suas experiências de aprendizagem, professores pré-serviço nos permitem compreender as inscrições discursivas, nas quais constroem representaçōes sobre o que seja língua, língua estrangeira, aprender/ser sujeito-aprendiz e ensinar/ser sujeitoprofessor nessa língua.

Partimos do pressuposto de que essas representações, por sua vez, permitem-nos perceber como o sujeito em formação se constitui discursivamente no devir deleuziano, ou seja, no entremeio do vivível 
e do vivido em relação à LE, no embate entre concepções/vozes sociais naturalizadas e contraditórias que perpassam as experiências vivenciadas na aprendizagem de uma LE.

Nessa perspectiva, este trabalho foi norteado pelas seguintes questôes:

Que efeitos de sentido são produzidos quando professores pré-serviço ${ }^{2}$ enunciam sobre suas experiências de aprendizagem de LE em seus memoriais?

Que representações de língua (estrangeira), processo de ensinoaprendizagem, sujeito-aluno e sujeito-professor eles constroem nesse processo enunciativo?

A partir da inscrição teórico-metodológica nos estudos do discurso, representaçōes são compreendidas como formações imaginárias ${ }^{3}$ (PÊCHEUX, 1969/1990). Portanto, tivemos como objetivo compreender como essas formações imaginárias funcionam, quando os professores pré-serviço enunciam em seus memoriais, desvelando tais representaçóes como um processo incompleto/inacabado, conforme pontua Deleuze, ou seja, perpassado pelo devir, pelas experiências de aprendizagem vivíveis e vividas, “sempre em via de fazer-se" (DELEUZE, 1997/2008, p.11). Afinal, o

devir não é atingir uma forma (identificação, imitação, Mimese), mas encontrar a zona de vizinhança, de indiscernibilidade ou de indiferenciação tal que não seja possível distinguir-se /.../ O devir está sempre "entre" ou "no meio" /.../ Não há linha reta, nem nas coisas nem na linguagem. A sintaxe é o conjunto dos desvios necessários criados a cada vez para revelar a vida nas coisas. (DELEUZE, 1997/2008, p.1112).

Nesse sentido, acreditamos que, ao usar memoriais de aprendizagem como prática de linguagem na formação do professor de LE pré-serviço, podemos melhor entender a relação que esse professor estabelece com a LE que aprende e com o (futuro) processo de ensino dessa língua.

A formação do professor de LE é atravessada por memórias discursivas ${ }^{4}$

\footnotetext{
2 Professores pré-serviço: licenciandos em Letras.

${ }^{3}$ Segundo Pêcheux, as formações imaginárias designam, nos processos discursivos, os lugares que os sujeitos atribuem a si e ao outro, a imagem que fazem de seu próprio lugar e do lugar do outro.

${ }^{4}$ A memória discursiva remete-se ao saber discursivo que torna possível todo dizer. Refere-se, pois, às possibilidades de dizeres que se atualizam no momento da enunciação, enquanto efeito de um esquecimento correspondente a um processo de deslocamento
} 
distintas, isto é, por conhecimentos articulados, superpostos e silenciados, os quais podem ser compreendidos destecendo-se os fios aparentemente univocais do discurso. Analisar memoriais de aprendizagem é, pois, uma forma de repensar e problematizar discursividades que circulam no contexto de formação de professores de LE e até que ponto elas podem influenciar as práticas de ensino e o modo pelo qual a aprendizagem é abordada nesse contexto.

Num primeiro momento, este artigo apresenta um breve estado da arte acerca de alguns estudos já desenvolvidos sobre memoriais e narrativas autobiográficas na área de formação de professores de LEs. Em seguida, apresentamos nossa concepção de memorial de aprendizagem a partir do arcabouço teórico arquitetado para esta pesquisa. Logo após, explicitamos a metodologia desenhada para dar conta da análise discursiva dos memoriais. Finalmente, apresentamos nossas considerações, discutindo os resultados da pesquisa e seus possíveis impactos para a Linguística Aplicada, especificamente na área do professor de LE.

\section{Breve estado da arte: memoriais de aprendizagem e forma- ção de professores de línguas}

Neste trabalho, os memoriais de aprendizagem, como parte constitutiva das narrativas autobiográficas (diários, memoriais de formação, cartas, portfólios etc.), são tomados enquanto um gênero discursivo (BAKHTIN, 1953/2003). ${ }^{5}$ Geralmente, o objetivo de sua escritura, por parte do professor formador, é proporcionar ao sujeito professor pré-serviço possibilidades de (res)significar e problematizar suas experiências de aprendizagem concernentes às LEs, assim como relacionar tais experiências aos conhecimentos que se espera que eles construam durante sua formação na universidade. Como professoras formadoras de um curso de Letras, em uma instituição federal de ensino superior, entendemos que os memoriais

da memória de significaçôes. A memória discursiva remete-se, pois, ao saber discursivo que torna possível todo dizer.

${ }^{5}$ Segundo Bakhtin (1953/2003), os gêneros são concebidos como formas comunicativas verbo-visuais, sociais e ideológicas, relativamente estáveis, que são produzidas em diversas esferas da atividade humana. Essas formas produzem significações por meio da acentuação valorativa, dos conteúdos temáticos e de marcas linguísticas, evidenciadas pelo estilo e pela forma composicional dos enunciados. 
devem ainda se configurar como um espaço para que esses sujeitos tomem uma posição (PÊCHEUX, 1997) diante da língua(gem), das LEs e do processo de ensino-aprendizagem. Essa tomada de posição, segundo Pêcheux, não é de modo algum "um ato imaginário" do sujeito, ou seja, é efeito da determinação da memória discursiva, colocada em funcionamento no processo enunciativo. A nosso ver, isso significa que tomar uma posição compreende a construção e sustentação de discursividades sobre a língua(gem) e seus modos de ensinar e aprender.

A valorização de escritas e pesquisas (auto)biográficas se inicia por volta dos anos 1970, quando ocorre uma mudança no paradigma científico com a recusa em se adotar análises meramente estruturais a fim de investigar aspectos humanos e sociais na formação de professores. Nesse sentido, o método autobiográfico pode ser visto como uma forma de encorajar o pensamento crítico e reflexivo pelos sujeitos (SCHÖN, 1983; DEWEY, 1933; ZEICHNER, 1981), uma vez que possibilita aos professores expressarem suas vozes, experiências, vidas e a forma como as compreendem. Segundo ressaltado pelos trabalhos de Goodson (1992), Cochran-Smith \& Lytle (1993), Nóvoa (1988), dentre outros, o método biográfico concebe os indivíduos como sujeitos que produzem sentido por meio da linguagem e não apenas como objetos a serem investigados pelos pesquisadores. Apesar de haver críticas sobre os métodos (auto)biográficos, aqueles que os defendem argumentam que eles promovem a reflexão, desenvolvem atitude crítica e encorajam a autonomia, já que permite aos escritores se reinventarem.

No Brasil, Passeggi, Souza \& Vicentini (2011), na esteira dos trabalhos realizados por Josso (2004), alegam que a pesquisa educacional com foco na escrita autobiográfica na formação de professores se expande a partir dos anos 1990, logo após o que tem sido denominado 'virada biográfica educacional'. ${ }^{6}$ Conforme esses autores, a escrita de si pode assumir diferentes gêneros acadêmicos, já consolidados em universidades brasileiras como método de avaliação, tais como: memoriais de formação, ensaios biográficos, diários etnográficos, relatórios, cartas, portfólios, para mencionar alguns.

\footnotetext{
${ }^{6}$ Cumpre ressaltar a realização, na Pontifícia Universidade Católica do Rio Grande do Sul - PUCRS, desde 2004, do Congresso Internacional de Pesquisa (Auto)biográfica (CIPA), que busca aprofundar e discutir a relevância de investigações científicas norteadas pelo método (auto)biográfico.
} 
Conforme Prado \& Soligo (2005), memoriais de formação são textos reflexivos e críticos, cujos conteúdos consistem de experiências e histórias de vida da formação profissional do indivíduo. No curso de Letras, quando o formador solicita ao licenciando um memorial de aprendizagem, de alguma forma, esse memorial deixa vir à tona nuances de sua formação enquanto (futuro) professor da língua. Isso nos possibilita afirmar que há um imbricamento entre os gêneros, na medida em que põem em cena uma escrita de si, deixando rastros tanto da aprendizagem da LE quanto do processo de ensiná-la. Isso posto, os memoriais de aprendizagem, tomados como corpus de nossas análises, não podem deixar de ser compreendidos como 'memoriais de formação', ainda que apresentem um objetivo mais específico, ou seja, a ressignificação, pelos professores pré-serviço, de suas experiências de aprendizagem da LE.

É importante salientar que esses memoriais são concebidos aqui como produçóes escritas historicamente situadas, permeadas por diferentes discursos. Nesse sentido, nosso gesto de interpretação visa investigar as vozes que sustentam as posições discursivas dos enunciadores. Assumimos que, assim como em qualquer outro gênero, os memoriais de aprendizagem são ideologicamente constituídos e determinados por suas próprias condiçóes de produção. Em nosso caso, isso implica que não podemos ignorar que esses textos carregam marcas de relaçôes assimétricas de poder, uma vez que foram escritos por alunos-licenciandos para professores formadores em uma instituição acadêmica. Isso pressupõe que os memoriais são escritos para um leitor que, independentemente de atribuir notas ao aluno, permanece como um avaliador de sua produção. Concordamos, assim, como Rajagopalan (2002), quando afirma que

O autor do memorial acha que está empenhado em um exercício de autobiografia no qual é ele que decide o que entra e não entra. Ledo engano. Ao submeter-se à exigência da instituição ele se entrega, de corpo e alma, ao universo cartesiano e às suas leis de conduta. (RAJAGOPALAN, 2002, p. 348).

\section{Desenho teórico-metodológico}

A formação de professores de línguas tem recebido, nos últimos anos, especial atenção nos estudos em Linguística Aplicada. Para se pensar essa formação, várias são as filiações teórico-metodológicas dos trabalhos desenvolvidos na área. 
No caso de nosso estudo, filiamo-nos a uma Linguística Aplicada inter/ transdisciplinar, que busca olhar a formação do professor de línguas pelo viés da discursividade, ou seja, como "um processo contínuo de (des)inscrição em discursos sócio-historicamente constituídos, de (des)identificaçôes com memórias discursivas, na e pela linguagem" (BRITO \& GUILHERME, 2013, p.25), "uma Linguística Aplicada que assume a dimensão política de suas atividades científicas" (GUILHERME, 2011, p.63).

Para os objetivos delineados neste estudo, nos apoiaremos em algumas noções da Análise do Discurso Francesa (ADF), representada pelos trabalhos de Michel Pêcheux (sujeito, discurso, intradiscurso/interdiscurso, representaçōes/formações imaginárias, memória discursiva, formação discursiva, tomada de posição), e nos estudos desenvolvidos pelo Círculo de Bakhtin (Análise Dialógica do Discurso - ADD), a partir das concepções de sujeito, enunciado, signo, dialogismo, polifonia, vozes e alteridade.

A ADD é uma terminologia cunhada no Brasil para se referir aos estudos desenvolvidos pelo Círculo de Bakhtin - um grupo de estudiosos russos tais como Mikhail M. Bakhtin, Valentin N. Voloshinov, Pavel N. Medvedev, dentre outros - cujo foco de estudo era discutir e problematizar projetos filosóficos em torno da concepção de língua(gem).

Numa perspectiva bakhtiniana, o enunciado é a unidade de comunicação verbal que permite que a língua(gem) seja tratada como um movimento de interlocução responsiva real e pode ser uma única palavra ou uma obra literária completa, em que múltiplos significados podem ser apreendidos (BAKHTIN, 1953/2003). Assim, não há significados únicos para os signos/ palavras analisadas em um enunciado. O sujeito do discurso é, assim, considerado como o responsável por atribuir sentidos às palavras, ou, nas palavras do autor: "Toda compreensão é prenhe de resposta e, de uma forma ou de outra, forçosamente a produz: o ouvinte torna-se o locutor" (BAKHTIN, 1953/2003, p.290).

Nesse sentido, os signos/as palavras só podem ser considerados a partir da interação entre sujeitos. Seu significado ocorre a partir da atitude responsiva que o interlocutor atribui ao enunciado. Por outro lado, essa atitude responsiva escapa ao controle do sujeito na medida em que se constitui um diálogo ilimitado e interminável entre os enunciados. Por isso, o outro participa na constituição de sentidos das palavras, o que nos leva à compreensão de que nossas palavras trazem em si vozes outras que dialogam entre si e nos permitem enunciar algo, ou seja, "as palavras dos outros 
introduzem sua própria expressividade, seu tom valorativo, que assimilamos, reestruturamos, modificamos" (BAKHTIN, 1953/2003, p.295). Em suma, "cada enunciado é pleno de ecos e ressonâncias de outros enunciados com os quais está ligado pela identidade da esfera da comunicação discursiva" (BAKHTIN, 1953/2003, p.297).

$\mathrm{Na}$ esteira do pensamento bakhtiniano, este estudo possui uma natureza que contempla as ordens descritiva, analítica e interpretativa dos dizeres enunciados pelos sujeitos participantes da pesquisa. Isso significa que os discursos produzidos pelos professores em seus memoriais de aprendizagem são investigados em sua dimensão dialógico-polifônica, são analisados de forma a se poder compreender como os enunciados proferidos pelos professores evocam vozes de diferentes espaços e diferentes discursos (polifonia), revelando, assim, as relações de alteridade entre essas vozes e que historicamente constituem os processos discursivos sobre sua aprendizagem de uma língua estrangeira. Esses discursos coexistem com outros discursos (dialogismo), provenientes de outras tomadas de posição, de outras formações discursivas, ${ }^{7}$ sendo que, no movimento no qual eles se entrelaçam, as palavras deixam revelar as vozes consoantes e dissonantes que os constituem.

Nessa perspectiva, a ADD representa uma possibilidade de se analisar relações dialógicas, que se estabelecem e que constituem espaços de tensão entre enunciados proferidos, levando-se em consideração que as vozes constitutivas de tais relações são equipolentes na medida em que uma não se sobrepõe a outra, mas todas funcionam de forma plenivalente (BAKHTIN, 1929/2008). O sujeito que enuncia é, pois, intrinsecamente povoado por uma multiplicidade de vozes e consciências de outrem, no limiar da interação verbo-social, de maneira plenivalente ("isto é, plenas de valor, que mantêm com as outras vozes do discurso uma relação de absoluta igualdade como participantes do grande diálogo") (BAKHTIN, 1929/2008, p.4) e equipolentes ("são consciências e vozes que participam do diálogo com as outras vozes em pé de absoluta igualdade”) (BAKHTIN, 1929/2008, p.5).

\footnotetext{
${ }^{7}$ Formação discursiva como "aquilo que numa formação ideológica dada, isto é, a partir de uma posição dada numa conjuntura dada, determinada pelo estado da luta de classes, determina o que pode e deve ser dito /.../" (PÊCHEUX, 1975/1997, p.160 - grifos do autor).
} 
Em estudos em que se pretendem analisar discursos, aspectos teóricos e metodológicos se imbricam, o que significa que noções teóricas são mobilizadas tanto para a constituição do corpus quanto para sua subsequente análise.

Neste estudo, quarenta e três (43) memoriais escritos foram coletados em 2006, 2009 e 2010 em uma universidade federal brasileira, em um Curso de Letras, nas seguintes disciplinas: Metodologia do Ensino de Línguas Estrangeiras (19 memoriais), Redação em Língua Inglesa (8 memoriais) e Conversação em Língua Inglesa (16 memoriais). Quando solicitados a escrever seus memoriais, os professores pré-serviço foram encorajados a (re) significar seu processo de aprendizagem da língua estrangeira. Ainda que os memoriais tenham sido parte do plano de avaliação de cada curso, cumpre ressaltar que os professores foram avaliados apenas pela realização da tarefa e não por seu conteúdo, tendo permitido e consentido o uso desses memoriais em nossa pesquisa.

Para o desenvolvimento da análise, sequências discursivas (SD) foram selecionadas a partir das regularidades reveladas nos discursos, o que nos permitiu examinar em quais formações discursivas suas práticas discursivas se inscrevem e os efeitos de sentidos instaurados nos processos enunciativos de seus dizeres. Em outras palavras, foi possível observar como as relações entre o intradiscurso e o interdiscurso se imbricam e se estabelecem, isto é, os sentidos verticais que escapam ao sujeito na materialidade linguística.

Vale ressaltar que, segundo Pêcheux (1969/1990), discurso não é um mero conjunto de frases, é materialidade específica da ideologia, é efeito de sentidos entre interlocutores, sendo que sua análise implica referi-lo ao conjunto de discursos possíveis a partir de um estado de condições de produção.

No que tange ao intradiscurso, Pêcheux o concebe como a dimensão linear do discurso, ou seja, o fio da formulação efetivamente produzida pelo enunciador. Já o interdiscurso é tomado como as (re)significaçôes, os deslocamentos do sujeito sobre o repetível, o 'já-dito', que revelam os efeitos da interpelação ideológica (Pêcheux, 1975/1997). Para Serrani (1998), realizar análises em nível intradiscursivo permite estudar "a relação materialidade discursiva-processo discursivo do dito com o que se disse antes e ao que se aponta" (SERRANI, 1998, p.158), e em nível interdiscursivo, permite estudar "o funcionamento da implicitação que é da ordem das determinações ideológicas e inconscientes, que constituem o sentido de todo discurso" (SERRANI, 1998, p.158). 


\section{Discutindo as representações}

As representaçôes construídas nos memoriais de aprendizagem - de língua (estrangeira), processo de ensino-aprendizagem, sujeito-aluno e sujeito-professor - parecem ser balizadas por uma representação mais ampla/ preponderante, ou seja: as escolas de ensino regular e o Curso de Letras na universidade se constituem como não-espaços para o aprendizado do inglês, que funciona discursiva e dialogicamente em oposição à representação de que os institutos de idiomas se constituem os espaços legítimos para o aprendizado do inglês.

Quando se referem à experiência de aprender a língua inglesa em escolas regulares, os professores pré-serviço deixam revelar a representação de que, nessas escolas, aprender essa língua é quase impossível, (d)enunciando alguns aspectos, tais como: metodologias tradicionais, professores despreparados, ausência de material adequado, aulas ministradas na língua materna etc., como pode ser observado nas seguintes sequências discursivas:

Infelizmente, todos os meus professores de inglês (tanto do ensino fundamental quando do médio) eram muito fracos, sem controle da turma ou da matéria, sem mencionar que raramente saíam do verbo to be. $\left(\mathrm{MG}_{-} 2009 \_\mathrm{CLI}^{8}\right)$

Não tenho muitas recordações desse momento importante no ensino de LE em minha formação básica, pois quando lembro deste verbo noto que não sei definir em qual série eu estava, se na $5^{\mathrm{a}}$, ou na $6^{\mathrm{a}}$, talvez na $7^{\mathrm{a}}$ ou $8^{\mathrm{a}}$. Sempre as mesmas aulas, só mudavam os professores. (M2_2006_MLE)

Outro fator muito importante que deve ser ressaltado no ensino fundamental é que o professor sempre estava "preso" ao livro didático, sem buscar novos contextos, métodos e abordagens de ensino. /.../ procurei uma escola de idiomas /.../ neste novo ambiente comecei a perceber as mudanças no ensino de língua estrangeira /.../ com a abordagem comunicativa de ensino. (M1_2006_MLE)

\footnotetext{
${ }^{8}$ Memorial Número Seis (6), coletado em 2009, na disciplina 'Conversação em Língua Inglesa' (CLI). MLE será usado para se referir aos memoriais coletados na disciplina 'Metodologia de Línguas Estrangeiras' e RLI para aqueles coletados na disciplina 'Redação em Língua Inglesa'.
} 
Nas primeiras disciplinas do Inglês tive bastante dificuldade, tanto com a parte gramatical como com a parte oral, pois até então só havia estudado Inglês em Escolas Públicas, onde a instrução era realizada somente na língua materna e não havia quase nenhuma oportunidade de uso comunicativo da língua estrangeira. (M3_2006_MLE)

Já quando se referem à experiência de aprender a língua inglesa na universidade, no Curso de Letras, os professores pré-serviço pontuam a heterogeneidade dos alunos no que se refere à proficiência oral, atribuindo a essa proficiência o lugar de maior obstáculo na sala de aula. Além disso, inscrevem-se numa discursividade em que o Curso de Letras é representado como uma esfera em que se prioriza a aprendizagem de 'como ser professor de língua inglesa', mas não da 'língua em si mesma’.

/... em relação às disciplinas de língua inglesa na universidade, o que eu posso dizer é que os professores são muito bem preparados para ministrar aulas, mas há um desnivelamento muito grande na proficiência dos alunos, o que acaba prejudicando tanto os mais proficientes quanto os menos. (M7_2010_CLI)

Este curso nos dá permissão para ensinar inglês, mas acredito que ele por si só não é suficiente para tornar um aluno fluente. Eu sou um bom exemplo, já que tenho apenas o nível intermediário de inglês. (M7_2009_RLI) ${ }^{9}$

As matérias em língua inglesa na Universidade não são condizentes com o propósito de curso, que é justamente formar professores capacitados para o mercado de trabalho e que proporcionarão aos seus alunos um processo de aprendizagem completo. A matéria de inglês /.../ não capacita os alunos possuírem o domínio da língua inglesa em sua totalidade, especialmente se eles nunca tiveram nenhum estudo auxiliar fora da escola, ou mesmo fora da faculdade. (M1_2009_CLI)

Ao enunciarem que nem as escolas regulares nem o Curso de Letras são vistos como espaços onde há a possibilidade de se aprender o inglês, os professores pré-serviço colocam em alteridade o ensino da língua nos institutos de idiomas, construindo a representação de que os institutos de

\footnotetext{
${ }^{9}$ Nossa tradução do original: "This course gives us permission to teach English, but I believe that it alone is not enough to make a student become fluent. I am a good example, since I only have intermediate level of English.”
} 
idiomas se constituem os espaços legitimos para o aprendizado do inglês. Esses institutos são, assim, concebidos como os melhores (senão os únicos) lugares para se aprender bem a língua inglesa, o que significa que esses professores evocam uma voz naturalizada - parte do discurso pedagógico sobre LEs no Brasil - que reforça sua legitimidade.

Em algumas narrativas, para enunciarem sobre os institutos de idiomas, os professores obliteram/apagam o que se poderia considerar como desvantagens e aspectos negativos das escolas regulares e do Curso de Letras, desvelando, assim, sentidos de admiração pelo ensino que é oferecido pelos institutos, apesar do contrassenso, do despropósito de uma atividade vivenciada e relatada por um dos professores:

Além da escola, tinha o instituto de idiomas, que enriqueceu muito meu inglês e me trouxe novas experiências. Eu estava na sétima série quando ganhei esse presente. Diziam que o inglês fora, como assim chamavam, era muito melhor, mais rentável. Infelizmente tenho de concordar. $\mathrm{O}$ instituto de idiomas fez com que meu inglês avançasse muitas braçadas de léguas. As professoras eram excelentes, os livros eram muito bons e o ambiente também propiciava um bom aprendizado. Um momento marcante foi a ida a um fast-food, onde tivemos de nos expressar em inglês - foi um fiasco, mas muito engraçado. O problema é que o pessoal da lanchonete não falava inglês. Hei, I want a cheesburger? Quê (M3_2009_CLI)

Cumpre observar que, mesmo sendo nomeada como um 'fiasco' (ou seja, "falha completa"), a atividade proposta pelo professor do instituto de idiomas não é significada de forma a retirar sua legitimidade, antes encontra no discurso lúdico uma maneira de se justificar como momento marcante.

Outro exemplo pode ser ilustrado por sequências discursivas nas quais os professores pré-serviço, ao enunciarem sobre as aulas de inglês na universidade, não veem as aulas ministradas apenas na língua inglesa como um aspecto positivo, mas como um suposto 'obstáculo' para a aprendizagem da língua. Assim, o uso da língua inglesa no espaço de sala de aula é discursivamente construído nas seguintes instâncias: i) no contexto das escolas regulares, o não-uso da língua inglesa nas aulas é considerado como a grande razão para o não-aprendizado da língua; ii) no Curso de Letras, o uso da língua inglesa como mediadora das aulas seria 'um pouco demais' para aqueles que não possuem conhecimento prévio (provenientes das escolas regulares); iii) finalmente (e tão somente) nos institutos de idiomas, o uso da língua estrangeira seria apresentado aos alunos na 'dosagem perfeita', 
nem mais, nem menos, mas na quantidade precisa para promover uma aprendizagem efetiva.

Hoje me sinto mais preparada fiz um cursinho complementar nessas Escolas de Idiomas, onde o método de ensino é bastante característico da abordagem áudio-oral /.../ Primeiro ouve o CD acompanhado da leitura silenciosa das frases, em seguida ler as frases e suas traduçōes, juntamente com o professor e depois fala aos colegas. Somente após o domínio da forma oral é introduzido à escrita, de forma que, há o desenvolvimento das quatro habilidades: ouvir, ler, falar e escrever. Pois na UFU, não tive muito apoio, a instrução do diálogo era apoiada em ilustrações pictóricas, miméticas o que para mim causava um grande desconforto, a ponto de ter que fingir que entendi determinada palavra para a professora parar de fazer mímica. A instrução era realizada totalmente na língua estrangeira /.../ (M3_2006_MLE)

Torna-se significativo, neste momento, para corroborar a inscrição desses sujeitos em uma memória discursiva que atribui aos institutos o lugar de soberania, perceber que, quando se referem às dificuldades encontradas nos institutos, eles culpam a si mesmos (e não os institutos) pelas falhas/faltas e por não alcançarem seus objetivos e suas metas, como pode ser observado aqui:

No segundo colegial, eu procurei uma nova escola de Inglês, /.../ com o ensino baseado nas repetiçōes, eu tive muita dificuldade, pois não é que eu não entendia o texto que era falado e visto no vídeo, mas eu tenho muita dificuldade em decorar, assim sempre que a professora pedia que eu fosse o primeiro a falar eu não conseguia, assim não via motivos para comparecer as aulas, realmente não foi uma experiência muito boa a minha aprendizagem em língua estrangeira. (M1_2006_MLE)

Intradiscursivamente, podemos observar que esse sujeito-professor em formação atribui a ele mesmo as falhas/faltas vivenciadas no instituto de idiomas, tanto que seus dizeres são enunciados na primeira pessoa do

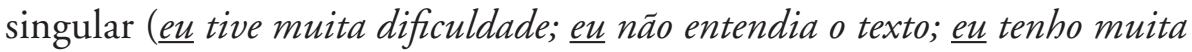
dificuldade em decorar; eu não conseguia). Interdiscursivamente, ficam implícitas as determinações ideológicas e inconscientes desse sujeito, permitindo observar que o efeito de sentido que se constitui é da ordem da denegação e do apagamento, ou seja, esse sujeito denega e apaga sua constituição lacunar como sujeito que busca se inscrever na discursividade de uma língua estrangeira. Em seu imaginário, o instituto de idiomas lhe proporciona o necessário para que o processo de ensino-aprendizagem da língua estrangeira ocorra de forma plena e completa. Se há falhas nesse 
processo, elas se encontram no próprio sujeito, ou seja, a 'completude' lhe é oferecida, se há 'incompletude', a mesma é significada como '(in)capacidade individual'. Por outro lado, foi possível observar, em vários memoriais, os sujeitos se inscrevendo numa discursividade na qual as falhas/faltas são creditadas às escolas regulares e à universidade.

$\mathrm{Na}$ dicotomia instaurada entre 'aprender inglês em escolas regulares/ Curso de Letras' e 'aprender inglês em institutos de idiomas', há vozes constitutivas do imaginário dos professores que apontam para uma desvalorização dos primeiros em relação aos últimos. Por um lado, as escolas regulares e a universidade seriam os espaços de métodos ineficientes, professores despreparados (ou, ironicamente, muito competentes/fluentes), condições precárias (ou, mais uma vez, ironicamente muito sofisticadas), ou seja, seriam os não-lugares para a aprendizagem da língua inglesa. Por outro lado, os institutos de idiomas seriam o espaço de inovação, de treinamento eficiente, dinamismo, boas atividades pedagógicas, perfeita infraestrutura e, consequentemente, de aprendizagem da LE.

Compreendemos que o que sustenta a coexistência de vozes conflitantes e dissonantes na dicotomia acima interpretada e, consequentemente o 'poder supremo' atribuído aos institutos de idiomas é a representação da fala como sinônimo de aprendizagem da LE. Há uma ressonância discursiva entre 'falar a LE' e 'saber a LE'. Em outras palavras, o que os sujeitos enunciadores parecem ressentir de suas experiências de aprendizagem, nas escolas ou na universidade, é do fato de não terem aprendido a falar fluentemente a língua inglesa, uma vez que imaginam/idealizam essa fluência pelo viés da completude, como um fenômeno constitutivo de qualquer falante:

Gostaria de melhorar na verdade todas as minhas habilidades, mas o que eu mais gostaria era de aprender a falar fluentemente, com desenvoltura, sem timidez e principalmente sem medo e sem vergonha de errar. Todos na vida cometem erros. Ninguém sabe tudo. (M5_2009_CLI)

Sei que para atingir meu objetivo, conseguindo fluência em Inglês, precisarei cursar uma escola particular, ou viajar para fora do país, pois ao longo da graduação, esse desejo será quase impossível de ser suprido. (M18_2006_MLE)

Atualmente estou no $6^{\circ}$ período /.../ Ainda este ano espero voltar a fazer um cursinho de inglês para melhorar meu nível. Quero ser fluente na língua inglesa /.../ espero continuar meus estudos e ter a oportunidade de estudar fora do Brasil /.../.(M7_2010_CLI) 
Ainda enfrento muitos impasses, não está tudo ajeitado. A habilidade que me causa mais terror e frustração é speaking. Nasceu com a convivência com muitas pessoas proficientes em inglês. Sinto como se tivesse que atravessar uma ponte e os meus amigos também, sendo a minha de madeira e a deles de concreto armado. (M3_2009_CLI)

Ainda que se inscrevendo no discurso da incompletude (Todos na vida cometem erros. Ninguém sabe tudo) e no discurso da falta e da exclusão (esse desejo será quase impossivel de ser suprido; Ainda enfrento muitos impasses, não está tudo ajeitado; A habilidade que me causa mais terror e frustração é speaking), o 'falar fluentemente' é legitimado tendo como referência os falantes nativos que, no imaginário dos enunciadores são aqueles que falam com desenvoltura, sem timidez e principalmente sem medo e sem vergonha de errar. Isso nos permite delinear a representação de que falar bem a lingua inglesa é possuir a proficiência do falante nativo, um falar que só será possível se o sujeito fizer um cursinho de inglês, se tiver a oportunidade de estudar fora do Brasil. Esse falante nativo seria, ainda, capaz de fornecer um 'contato real e direto' com a língua outra:

Nesse ínterim, desde quando entrei na faculdade até agora, tive a oportunidade de conhecer pessoas de Londres e Chicago /.../ Eles vieram visitar o Brasil e se hospedaram na minha casa. Foi uma experiência interessante e ótima para colocar em prática o que eu já havia aprendido. (M6_2006_MLE)

Eu costumava estudar na [nome do instituto de idiomas] toda sexta-feira para conversar com falantes nativos /.../ assim eu podia ter um dia extra em contato direto com a língua. Isso me ajudou mais do que eu esperava. (M2_2009_RLI) ${ }^{10}$

Assim, somos levadas a perceber outra representação constitutiva de suas memórias discursivas quando enunciam em seus memoriais sobre sua aprendizagem da LE: ter uma experiência em um pais falante da língua inglesa seria 'a cereja do bolo para os aprendizes não-nativos da língua-alvo:

\footnotetext{
${ }^{10}$ Nossa tradução do original: "I used to go to [name of the private institute] every Friday to speak to native speakers /.../ so that I could have an extra day in direct contact with the language. This helped more than I could expect."
} 
Tenho estudado inglês por muitos anos. Apesar de me considerar um aluno de inglês dedicado, pois eu gosto, às vezes sinto que preciso ir ao exterior para "finalizar" o processo de aprender uma outra língua, conseguir mais fluência /.../eu nunca parei de tentar melhorar minhas habilidades no inglês /.../ como escutar o que eles (falantes nativos) ouvem e conversar com outros falantes de inglês pela Internet. (M3_2009_RLI) ${ }^{11}$

A ilusão de completude no aprendizado do inglês (compreendido aqui como 'falar como o nativo'), que poderia ser alcançada apenas nos institutos de idiomas ou em experiências no exterior, entra em colapso com a percepção da falta, com os furos e as fissuras (re)veladas em dizeres, nos quais se aponta que a aprendizagem de uma língua é um "processo complexo", em que há "barreiras" imprevisíveis e incontroláveis.

Isso nos faz perceber que os sujeitos não são homogêneos e que a linguagem não é transparente, um mero sistema de códigos. Sujeitos e linguagem são histórica, ideológica e socialmente constituídos e, por conseguinte, situados. Isso significa que o processo de aprendizagem de uma língua estrangeira (e até mesmo da língua materna) é inevitavelmente um processo de tensão, conflitos e enfrentamentos, na medida em que diferentes vozes (provenientes da cultura, da história e da própria subjetividade) são evocadas. Esse processo envolve, pois, confrontos, a capacidade de se lidar com o 'diferente' e com os deslocamentos da subjetividade.

Mas já nessa época, eu conseguia ler e escrever em Inglês, mas falar sempre foi a minha grande barreira na aprendizagem de língua estrangeira, eu sempre penso em inglês, mas quando vou falar há barreiras, isso prova com a nossa própria cultura que está arraigada, e quando falamos outra língua que não é a nossa materna é muito complexo o processo. (M1_2006_MLE)

No próximo semestre farei as disciplinas: redação em LF, conversação e Prática de Ensino de Francês. E fico me perguntando, será que estou pronto para dar aulas de LE??? Lá no fundo do meu subconsciente a resposta é NÃO. Mas não fico triste, pois sei que o pouco que aprendi, até com as "tias" lá da educação

\footnotetext{
${ }^{11}$ Nossa tradução do original: "I have been studying English for many years. Although I consider myself a dedicated student of English, because I like it, sometimes I feel I need to go abroad to "finish" the process of learning another language, to get more fluency_.... I have never stopped trying to improve my English skills /... / like listening to what they (native speakers) listen and talk with other speakers of English throughout the Internet."
} 
básica, servirá muito em minha vida. O "Talvez" agora é um sentimento que me acompanha quando penso em LE. Talvez um dia serei "comunicativo" em outra língua...enfim. (M2_2006_MLE)

As sequências discursivas acima traduzem o movimento tenso/ conflitivo dos sujeitos no processo enunciativo. Pode-se observar o quão é difícil para eles se constituírem sujeitos de uma LE e enunciarem sobre essa constituição. Eles desejam alcançar uma proficiência sublimada e idealizada, mas esse desejo (complexo) é atravessado por sentidos de impossibilidade (quando falamos outra língua que não é a nossa materna é muito complexo o processo; será que estou pronto para dar aulas de LE?; Talvez um dia serei "comunicativo" em outra lingua...enfim.).

Mas o questionamento que se coloca é: como podem os professores pré-serviço resistir aos furos, aos lapsos e às faltas que permeiam sua memória discursiva e sobre os quais não têm controle? Para amenizá-los/atenuá-los, eles se inscrevem na dispersão dos discursos para resistir e exercitar seus lugares nos universos discursivos nos quais participam (GUILHERME, 2010). Isso pode ser observado na sequência discursiva a seguir, em que o sujeitoprofessor em formação na universidade revela seu estado de 'devir (odisseia), a experiência tensa e conflituosa de se aprender uma LE (limitaçôes, lutas), mas mesmo assim a ela resiste, inscrevendo-se no discurso da perseverança (não quero desistir desse direito que é aprender uma outra língua.)

Assim, chega aos tempos atuais, minha odisseia com o aprendizado de LE, levando-me a concluir que tenho muitas limitações e muitas lutas pela frente, uma vez que não quero desistir desse direito que é aprender uma outra língua. (M4_2006_MLE)

\section{Palavras finais}

Ao estabelecerem uma dicotomia entre 'escolas regulares e curso de Letras na universidade' como não lugares de aprendizagem de inglês e 'institutos particulares de idiomas' como lugares legítimos de aprendizagem de inglês no Brasil, ancorados pela representação de fala nativa como sinônimo de conhecimento de LE, os professores pré-serviço se inscrevem no discurso da ausência e no da falta, revelando seu estado de 'devir' como professores/aprendizes de inglês que estão incessantemente buscando uma proficiência idealizada e desejada. 
O discurso da ausência é evocado para enunciar acerca da representação de que os professores pré-serviço não aprenderam nada (ou quase nada) de suas aulas de inglês nas escolas regulares ou na universidade. Ou seja, eles simplesmente apagam qualquer experiência que tiveram como se a única coisa que estudaram (por mais de quatro anos) fosse o verbo to be. No Brasil, o enunciado 'tudo o que aprendemos na escola é o verbo to be, ano após ano' se tornou um 'jargão', isto é, uma naturalidade discursiva, socialmente enunciada a fim de explicar a situação precária do ensino de inglês em escolas regulares. Contudo, o que observamos, a partir dos dizeres dos professores pré-serviço, é que seu desejo de alcançar um nível 'perfeito' de fluência em inglês encontra nas escolas regulares um álibi. Esclareçamonos. No intuito de significar suas experiências de aprendizagem da língua inglesa, os professores pré-serviço se inscrevem em uma memória discursiva que priva de legitimação algumas práticas de ensino cujo foco não seja o desenvolvimento da proficiência oral. Eles simplesmente homogeneízam todas as práticas de ensino e aprendizagem (como se apenas os professores mudassem ao longo dos anos...) e se recusam a ver qualquer possibilidade de aprendizagem nesses contextos.

O curso de Letras, por sua vez, não é considerado um lugar bom e apropriado para se aprender inglês, haja vista que seu propósito maior seria a formação do professor. E aqui defendemos que tal argumento usado pelos professores pré-serviço parece vir do confronto estabelecido entre a posição discursiva de mero 'aprendiz de LE' x a posição de 'professor de línguas préserviço'. Posições das quais esses sujeitos são agora interpelados a enunciar, mobilizando, para isso, diferentes perspectivas concernentes à aprendizagem de uma LE.

O discurso da falta é baseado na representação do inglês como uma lingua inatingivel, pois seu 'real conhecimento' está fora do sujeito-aprendiz (o qual desempenharia um papel passivo em relação à aprendizagem), uma vez que é idealizada como constructo perfeito e transparente. Trata-se de um objeto fechado e exterior, como se pudesse haver alguma realidade não mediada e construída pela linguagem.

Acreditamos que ambos os discursos podem ser considerados perversos, já que impedem que os professores pré-serviço se vejam como enunciadores na LE, pois revelam o quão difícil é para aprendizes não nativos de inglês (e futuros professores) aceitar sua incompletude, a qual, inclusive, é parte de sua língua materna. Nesse sentido, eles negam que são sujeitos 
não nativos que estão inscritos no discurso de outra língua, uma língua que não é a sua.

Compreendemos que essas inscrições discursivas deveriam ser amplamente abordadas em contextos de formação de professores de LEs, por meio, por exemplo, de memoriais de aprendizagem como os que aqui investigamos. Frequentemente, tais contextos se limitam a prescrever aos professores o 'que' e 'como' devem fazer em suas aulas, não abrindo espaço para que suas vozes sejam ouvidas, a fim de que discursos naturalizados sejam problematizados e que sua incompletude (constitutiva) seja assumida. ${ }^{12}$

Uma palavra final se faz necessária sobre a relevância de estudos dessa natureza para a Linguística Aplicada, na área de formação de professores de línguas, ou seja, que busca investigar o uso da linguagem situada em contexto de formação. Acreditamos que os memoriais possam ser significativos não para 'resgatar' memórias intocáveis ou para 'descobrir a voz de um indivíduo', mas para possibilitar a captura de fios que constituem os movimentos de (des) identificação dos sujeitos com as línguas (e, portanto, os sucessos e fracassos concernentes a sua aprendizagem). Os memoriais de aprendizagem são, pois, um lugar onde as vozes da história, da cultura, da(s) política(s) podem ser ouvidas. Um lugar em que podemos compreender que a

memória é uma bagagem de cacos. Nossas lembranças são estilhaços. Ora realçamos detalhes, ora esquecemos outros. A completude é uma ilusão. Devemos aprender a conviver com os retalhos do passado e ter em mente que as nossas lembranças são mais invenção do que realidade. Os fatos se perdem, mas a experiência fica ancorada em algum lugar de nossas vidas - nós a carregamos e nem a percebemos. (M3_2009_EC)

\footnotetext{
${ }^{12}$ Cumpre destacar, no escopo das pesquisas desenvolvidas em Linguística Aplicada, os trabalhos de Romero $(2008,2010)$ e Medrado \& Reichmann (2012), que contemplam a formação do professor de línguas, levando em consideração as (auto)biografias em sua constituição identitária.
} 


\section{Referências}

BAKHTIN, M. (1953). Estética da criação verbal. Trad. Paulo Bezerra. São Paulo: Martins Fontes, 2003.

BAKHTIN, M. (1929). Problemas da poética de Dostoiévski. Trad. Paulo Bezerra. 3.ed. Rio de Janeiro: Forense Universitária, 2008.

BRITO, C. C. P. \& GUILHERME, M. F. F. Linguística Aplicada e Análise do Discurso: possíveis entrelaçamentos para a constituição de uma epistemologia. Cadernos Discursivos, Catalāo/GO, v.1, n.1, p.17-40, ago./dez. 2013.

BUENO, B. O. O método autobiográfico e os estudos com histórias de vida de professores: a questão da subjetividade. Educação e Pesquisa, São Paulo, v.28, n.1, p.11-30, 2002.

COCHRAN-SMITH, M. \& LYTLE, S. Inside/Outside: teacher research and knowledge. New York: Teachers College Press, 1993.

DELEUZE, G. (1997). A literatura e a vida. In: DELEUZE, G. Crítica e Clínica. Trad. Peter Pál Pelbart. São Paulo: Editora 34, 2008. p.11-16.

DEWEY, J. How We Think. New York: D. C. Heath, 1933.

GOODSON, I. (Ed.). Studying Teachers' Lives. London: Routledge, 1992.

GUILHERME, M. F. F. Da formação pré-serviço à prática em-serviço do professor de língua inglesa: a falta constitutiva. Trabalhos em Linguistica Aplicada, Campinas, vol.49, n.1, p.185-204, 2010.

GUILHERME, M. F. F. Bakhtin e os estudos em Linguística Aplicada. In: STAFUZZA, G. (Org.). Slovo - O Círculo de Bakhtin no Contexto dos Estudos Discursivos. Curitiba: Appris, 2011. p.59-78.

JOSSO, M. C. Experiências de vida e formação. São Paulo: Cortez, 2004.

MEDRADO, B. P. \& REICHMANN, C. L. (Org.). Projetos e práticas na formação de professores de língua inglesa. João Pessoa: Editora Universitária, 2012.

NÓVOA, A. A formação tem de passar por aqui: as histórias de vida no projeto Prosalus. In: NÓVOA, A. \& FINGER, M. (Org.). O método (auto)biográfico e a formação. Lisboa: MS/DERHS/CFAP, 1988. p.107-129.

PASSEGGI, M. C.; SOUZA, E. C. \& VICENTINI, P. P. Entre a vida e a formação: pesquisa (auto)biográfica, docência e profissionalização. Educação em Revista, Belo Horizonte, v.27, n.01, p.369-386, 2011.

PÊCHEUX, M. (1969). Análise Automática do Discurso (AAD-69). In: GADET, F. \& HAK, T. (Org.). Por uma Análise Automática do Discurso: uma introdução à obra de Michel Pêcheux. Trad. Bethania S. Mariani et al. Campinas: Ed. da UNICAMP, 1990. p.61-161. 
PÊCHEUX, M. (1975). Language, Semantics and Ideology: Stating the Obvious. Translated by Harbans Nagpal. Hong Kong: The Macmillan Press LTD, 1982. PÊCHEUX, M. (1975). Semântica e Discurso: uma crítica à afirmação do óbvio. Trad. Eni Puccinelli Orlandi et al. Campinas: Ed. da UNICAMP, 1997.

PRADO, G. \& SOLIGO, R. Memorial de formação: quando as memórias narram a história da formação... In: . (Org.). Porque escrever é fazer história: revelações, subversões, superações. Campinas, SP: Graf, 2005.

RAJAGOPALAN, K. A confecção do memorial como exercício de reconstituição do self. In: MOITA LOPES, L. P. \& BASTOS, L. C. (Org.). Identidades: recortes multi e interdisciplinares. Campinas, SP: Mercado de Letras, 2002. p.339-349.

ROBERTS, B. The Biographical Research. Philadelphia: Open University Press, 2002.

ROMERO, T. R. S. Linguagem e memória no construir de futuros professores de inglês. Revista Brasileira de Linguística Aplicada, v.8, p.401-420, 2008.

ROMERO, T. R. S. Autobiografias de professores de inglês: o entretecer de memória e narrativa na constituição da identidade profissional. In: CELANI, M. A. A. (Org.). Reflexôes e açôes (trans)formadoras no ensino-aprendizagem de inglês. Campinas: Mercados de Letras, 2010. p.141-172.

SCHÖN, D. The Reflective Practitioner. How professionals think in action. London: Temple Smith, 1983.

SERRANI, S. M. Abordagem transdisciplinar da enunciação em segunda língua: a proposta AREDA. In: SIGNORINI, I.; CAVALCANTI, M. C. (Org.). Linguística Aplicada e Transdisciplinaridade. Campinas: Mercado de Letras, 1998. p.143-167. SOUZA, L. C. (Auto)biografias na formação de docentes: entre concepções educativas e procedimentos de avaliação. 2007. 173f. Dissertação (Mestrado em Educação) Faculdade de Educação da UFMG, Belo Horizonte, 2007.

ZEICHNER, K. Reflective teaching and field-based experience in teacher education. Interchange, n.12, p.1-22, 1981.

Data de submissão: 19/03/2014. Data de aprovação: 11/06/2014. 
